\title{
Evaluation of strength characteristics for palm kernel oil - based polyurethane (PKO-P) as a ground improvement method
}

\author{
Diana Che Lat *, Ismacahyadi Bagus Mohamed Jais, Kamaruzzaman Mohammed, \\ Bahardin Baharom, Nastasa Samat, Atiqah Najwa Zainuddin \\ Department of Geotechnical and Transport, Faculty of Civil Engineering, Universiti Teknologi Mara, 81750, Masai, Johor, Malaysia
}

* Corresponding author: dianacl@johor.uitm.edu.my

\section{Article history}

Received 27 November 2016

Accepted 22 December 2016

\section{Graphical abstract}
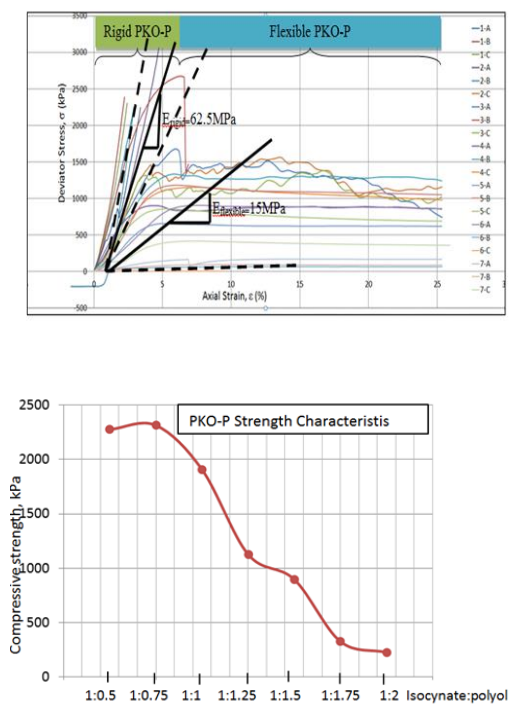

\begin{abstract}
Development on soft ground area cannot be avoided at certain area especially nearby coastal or marine area. At urban areas, most of the land has been fully developed and very limited space available, therefore area nearby marine region has to be explored to cater increasing in population in certain country. It is very crucial to stabilize the soft ground before any construction carried out to ensure the structure would be founded on the stable foundation system. Foundation system commonly established for deep soft ground is a pile foundation. There are certain cases whereby pile foundation system failed after completion of structure and the building has been accommodated or been utilized. It causes large settlement which contributes to the failure of structure such as longitudinal crack, sinkholes, beam fractured and so forth. Rectification works have to be done to restore foundation strength thus to prevent further settlement which can cause collapse or major failure of structure. Rectification works that commonly being done nowadays is underpinning pile whereby new pile being installed in between the existing pile to stabilize the foundation and prevent further settlement. This method rather wearisome to be carried out since it involves major excavation and disturbs the existing structure and the surrounding. Therefore it is proposed to carry out Palm Kernel Oil Based Polyurethane (PKO-P) Pile injection to overcome this problem. PKO-P pile injection is a lightweight material to prevent further settlement and the rectification works can be done very fast. No excavation is required and only a small diameter of hole is drilled on the existing slab foundation before injection of PKO-P Pile. PKO-P is a polyurethane processed from palm kernel oil which is renown of the sustainability and green materials. In this research, Unconfined Compression Test been have conducted on few samples of PKO-P materials with different ratio of polyol and isocyanate to determine the compressive strength characteristics for PKO-P materials as such to evaluate the performance of the PKO-P for ground improvement. From the test that has been done, the compressive strength achieves its maximum strength at isocyanate to polyol ratio of 1:0.75 with maximum compressive strength of $2.3 \mathrm{MPa}$. PKO-P shows rigid characteristics at this maximum strength which produce strong material, able to resist deformation but brittles beyond the maximum stress. With further increasing amount of polyol, PKO-P shows flexible characteristics whereby it undergoes deformation but they tend not to break beyond the maximum stress. Higher elastic modulus recorded for rigid type PKO-P compare to flexible type PKO-P.
\end{abstract}

Keywords: Palm kernel oil-based polyurethane, soft ground, settlement, ground improvement

\section{INTRODUCTION}

Soft cohesive soil is a fine soils where the particles are finer than $0.06 \mathrm{~mm}$ and are typically flaky in shape and so have considerable surface area such as silts and clays. Soft cohesive soil as a support medium for structure will undergo two types of problem if it is not properly investigated and treated with regards to shear failure and compressibility. Shear failure will occur when the rupture surfaces develop due to the shear strength of soil being exceeded. On the other hand, problems of compressibility occurred when a change in volume is induced in all soils when the external loads are increase in soft soil which produce serious settlement problem (Whitlow, R., 2004).
Various types of ground improvement and stabilization method have been investigated to stabilize soft cohesive soil such as excavate and replace, PVD, pile embankment, stone column, lime stabilization etc. Nevertheless, most of these ground improvement do not really suita2ble to improve ground failure of existing structure. It is because construction of this ground improvement more or less will damage the existing structure and mostly suitable for new development. Method of PU injection will minimize the disturbance to the existing structure since small diameter of hole required to insert the steel column in order to inject PU. It is lightweight material which will reduce the overburden to the underlying soil yet the stiffness of soil is increase. Most of PU used nowadays produced from petrochemical based which is undergone depletion in the production and the chemical process to produce this type of PU is complex and therefore the cost is high. In this study, PU 
used are from palm kernel oil-based which is very sustainable, environmental friendly and the chemical process to produce palm kernel oil-based PU is simple therefore, it is cost effective (Badri, K., 2012).

Polyurethane is produced by exothermic reaction between alcohols with two or more ractive hydroxyl (-OH) groups per molecule (diols, triols, polyols) and isocynates that have more than one reactive isocynate group (-NCO) per molecule (diisocynates, polyisocynates). The chemical reactions between polyols and isocynates are shown below:

\section{$\mathrm{R}-\mathrm{N}=\mathrm{C}=\mathrm{O}+\mathrm{R}$ '-O-H $\rightarrow$ R-NH-C(O)-O-R (Badri, K., 2012). Isocyanate Polyol Polyurethane}

Polyol has more than two reactive hydroxyl groups, adjacent longchain molecules become linked at intermediate points. These crosslinks create a stiffer polymer structure with improved mechanical characteristics which is exploited in development of rigid polyurethane.

\section{OBJECTIVE}

This research is executed with the aim to achieve the following objectives:

1) To conduct Unconfined Compression Test on PU palm kernel oilbased (PKO-P) with different ratio of polyol to isocynate to determine compressive strength characteristics index and its suitability to stabilize soft cohesive soil.

2) To select the optimum ratio of polyurethane in order to suit the application of ground improvement method.

\section{METHODOLOGY}

Polyurethane formed by reaction between polyol and isocynate. Polyol in this research is produced from palm kernel oil-based whilst isocynate is produced from petrochemical based. Ratio between isocynate to polyol used in this research are 1:0.5, 1:0.75, 1:1, 1:1.25, 1:1.5, 1:1.75 and 1:2. The materials mixed in a steel cylinder mould and stirred thoroughly. Very fast reaction occurred through the mix of both materials and it hardens immediately.

\section{Test Procedure}

Estimation of compressive strength of PKO-P due to certain load or other structures imposed on it required special laboratory test named Unconfined Compression Test (UCT). The laboratory test has been conducted to determine strength characteristics of PKO-P samples. The sample size for this test is $50 \mathrm{~mm}$ diameter and $110 \mathrm{~mm}$ length. The excess at top and bottom of the sample were trimmed to have smooth surface for testing. During mixing of the materials, whenever steel been used as a mould, room temperature should be controlled within 20 degree Celsius to prevent heat transfer.

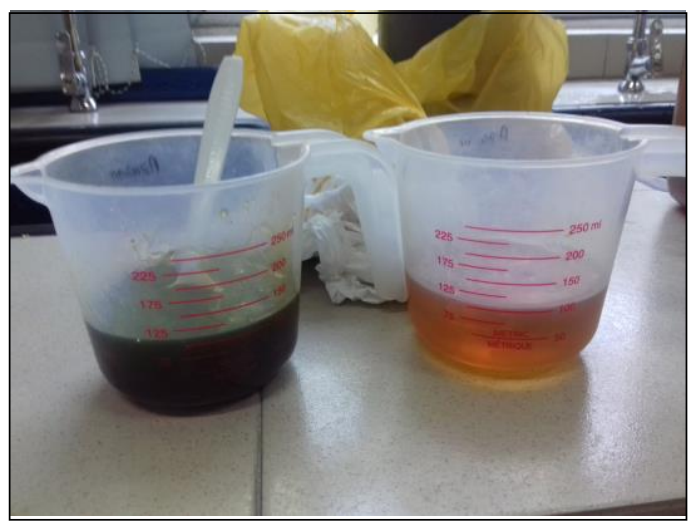

Fig. 1: Volume of polyol and isocynate measured in the measuring cup.
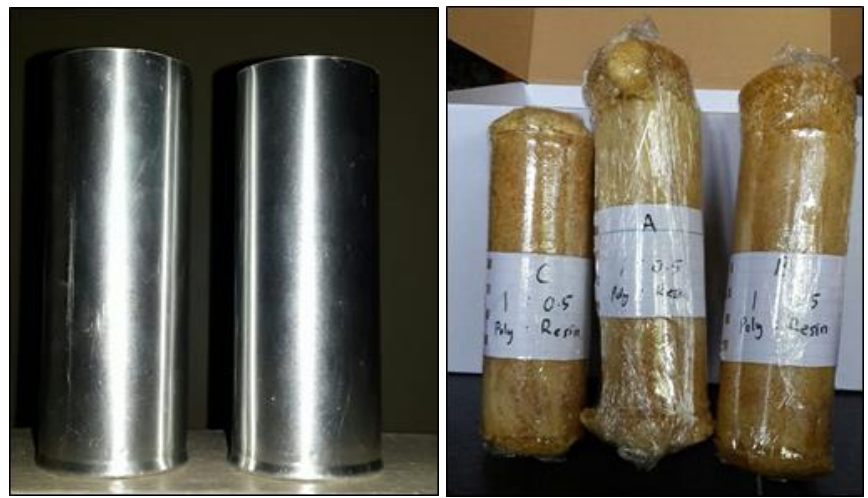

Fig. 2 Steel cylinder mould used to mix the materials.
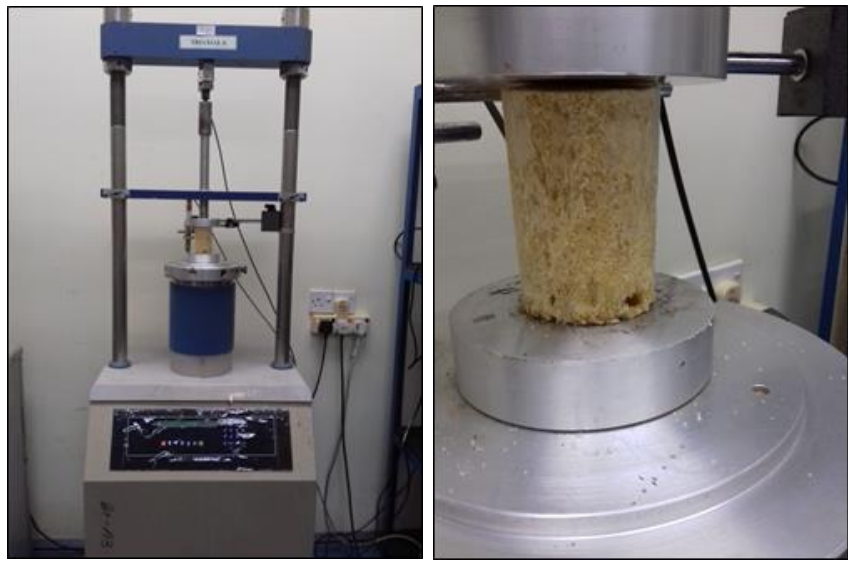

Fig. 3 Unconfined Compression Test Machine and PKO-P sample (Before test conducted)

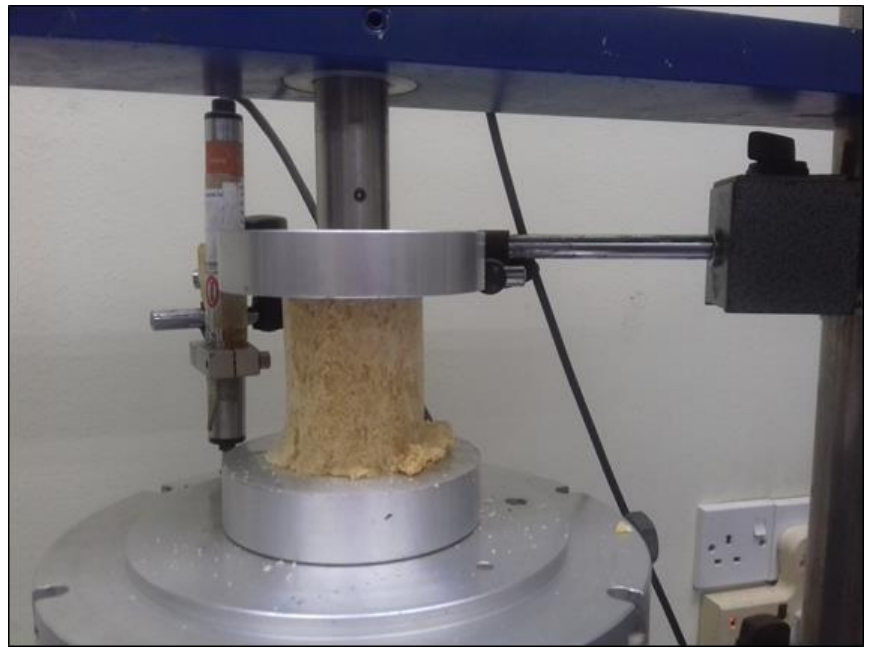

Fig. 4 Unconfined compression test machine and PKO-P sample (after test conducted).

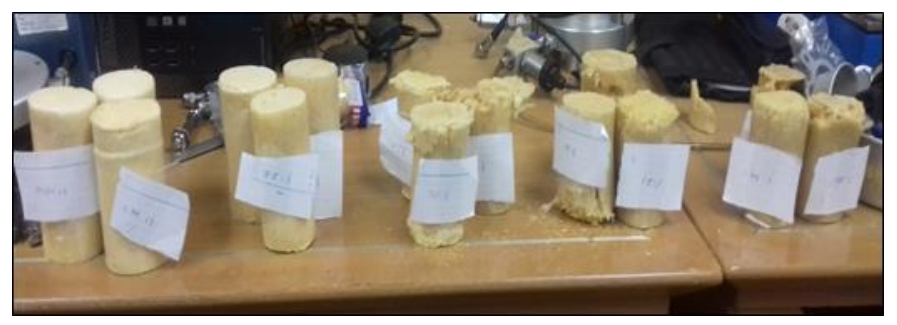

Fig. 5 Samples of PKO-P with different ratio of isocynate to polyol after UCT test been conducted. 


\section{RESULTS AND DISCUSSION}

From strength characteristics index shown in Figure 7, at the initial stage, the strength increase with increasing volume of polyol until it reaches maximum strength at isocynate to polyol ratio of 1:0.75. Beyond this ratio, the strength decrease with increasing volume of polyol. At isocynate to polyol ratio of 1:0.25, the PKO-P mix is soft enough thus the test cannot be performed. Therefore, isocynate to polyol ratio of 1:0.75 is the optimum ratio that is applicable for future field test with maximum compressive strength of $2.3 \mathrm{MPa}$. High density recorded for rigid PKO-P which is about $0.37 \mathrm{Mg} / \mathrm{m} 3$ to $0.47 \mathrm{Mg} / \mathrm{m} 3$ whilst flexible PKO-P recorded slightly lower value ranging from $0.26 \mathrm{Mg} / \mathrm{m} 3$ to $0.30 \mathrm{Mg} / \mathrm{m} 3$. Elastic modulus for both rigid and flexible PKO-P are shown in stress-strain plot of Figure 6, where the values are 62.5MPa and $15 \mathrm{MPa}$ for rigid and flexible $\mathrm{P}-\mathrm{KOP}$ respectively.

From stress-strain plot as shown in Figure 6 and Table 1, behavior of PKO-P varies with respect to the isocynate to polyol ratio. From the stress-strain plot, higher amount of isocynate show rigid characteristic of PKO-P which produce strong material but brittle. For rigid PKO-P as shown in Figure 6, it takes a lot of force to break this sample, but this sample cannot stretch very far before it breaks. A material like this which is strong, but cannot deform very much before it breaks is called brittle. Rigid PKO-P can withstand a good deal of stress, but cannot withstand much elongation before breaking. The gradient of the slope is very steep, means that it takes a lot of force to deform a rigid plastic, thus it has high elastic modulus. All in all, rigid PU tend to be strong, resist deformation but brittles beyond the maximum load. Photos of the rigid type of PKO-P after test are shown in Figure 8.

Flexible PKO-P different from rigid PKO-P in such a way that it undergoes deformation but they tend not to break. The ability to deform keeps it from breaking. Initial modulus is quite high, thus it will resist deformation at the initial stage, but if enough stress is imposed on a flexible PKO-P, it will eventually deform. Photos of flexible type of PKO-P after test are shown in Figure 9.

Table 1 Behavior of PKO-P varies with respect to the isocynate to polyol ratio

\begin{tabular}{|c|c|c|c|c|c|c|c|c|}
\hline \multirow{2}{*}{$\begin{array}{c}\text { Sample } \\
\text { No }\end{array}$} & \multirow{2}{*}{$\begin{array}{l}\text { Isocynate: } \\
\text { Polyol ratio }\end{array}$} & \multirow{2}{*}{$\begin{array}{c}\text { Density, } \rho \\
\left(\mathrm{Mg} / \mathrm{m}^{3}\right)\end{array}$} & \multicolumn{4}{|c|}{ Compressive strength $(\mathrm{kPa})$} & \multirow{2}{*}{$\begin{array}{c}\text { Elastic } \\
\text { Modulus } \\
\text { (MPa) }\end{array}$} & \multirow{2}{*}{$\begin{array}{c}\text { PKO-P } \\
\text { Type }\end{array}$} \\
\hline & & & A & B & $\mathrm{C}$ & Average & & \\
\hline 1 & $1: 0.5$ & 0.47 & 2245 & 2284 & 2303 & 2277 & \multirow{2}{*}{62.5} & Rigid \\
\hline 2 & 1:0.75 & 0.37 & 3155 & 2231 & 1558 & 2315 & & Rigid \\
\hline 3 & $1: 1$ & 0.30 & 1675 & 2668 & 1380 & 1908 & \multirow{5}{*}{15} & Flexible \\
\hline 4 & $1: 1.25$ & 0.27 & 899 & 1331 & 1150 & 1127 & & Flexible \\
\hline 5 & $1: 1.5$ & 0.26 & 654 & 1179 & 856 & 896 & & Flexible \\
\hline 6 & $1: 1.75$ & 0.28 & 903 & 62 & 9 & 325 & & Flexible \\
\hline 7 & $1: 2$ & 0.30 & 167 & 92 & 414 & 224 & & Flexible \\
\hline
\end{tabular}

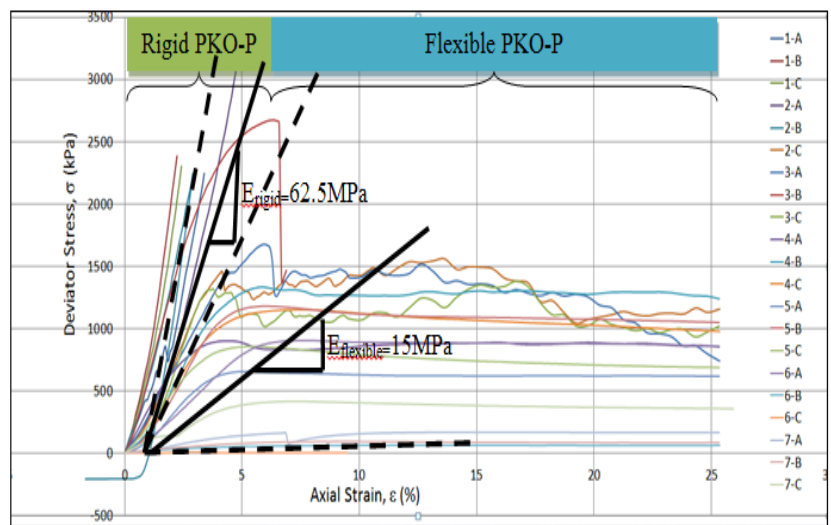

Fig. 6 Stress- Strain Plot

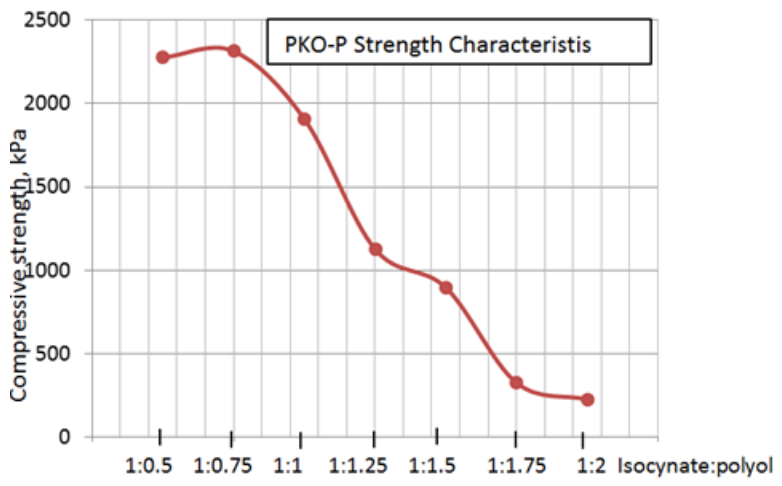

Fig. 7 PKO-P Strength characteristics graph

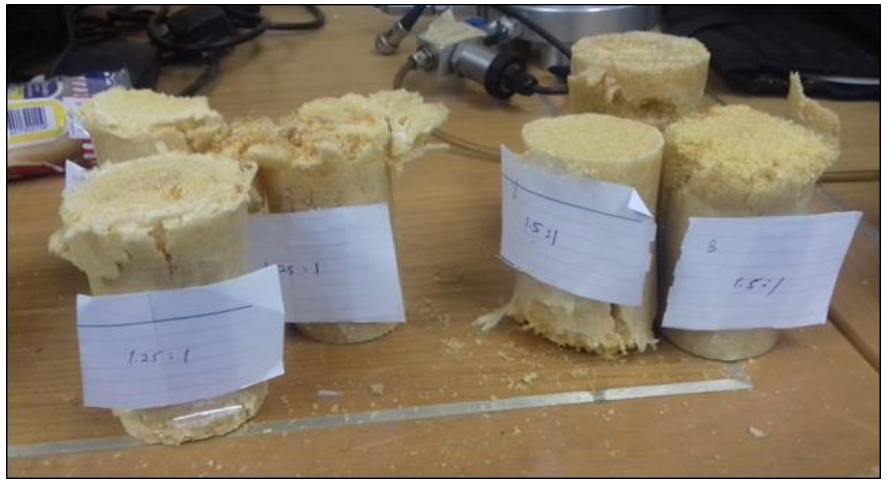

Fig. 8 Samples with high ratio of isocynate compare to polyol

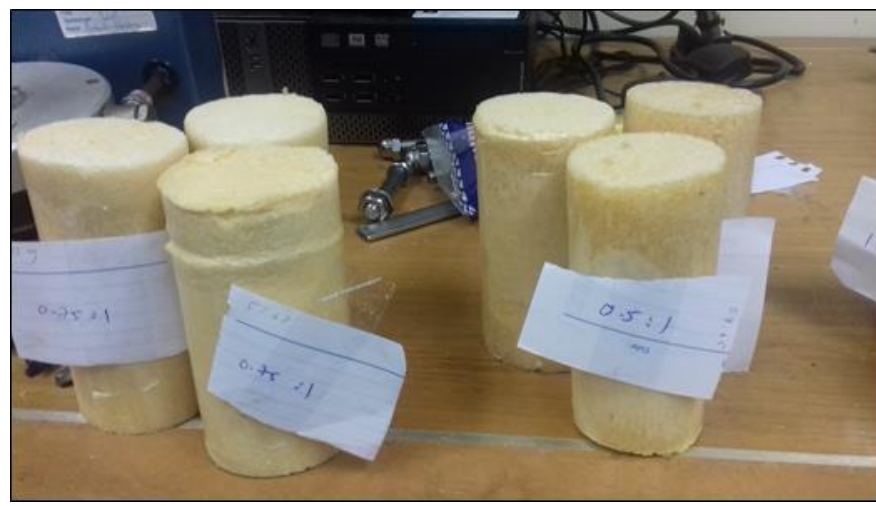

Fig. 9 Samples with low ratio of isocynate compare to polyol 


\section{CONCLUSION}

Unconfined Compression Test was conducted on PU palm kernel oil-based (PKO-P) with different ratio of isocynate to polyol in order to determine its compressive strength characteristics index. The compressive strength achieves its maximum strength at isocynate to polyol ratio of 1:0.75. PKO$P$ shows rigid characteristics at this maximum strength which produce strong material, able to resist deformation but brittles beyond the maximum stress. Beyond this, PKO-P shows flexible characteristics whereby it undergoes deformation but they tend not to break. Maximum compressive strength for PKO-P can achieve up to $2.3 \mathrm{MPa}$ with modulus elasticity of $62.5 \mathrm{MPa}$. Field test is recommended to be conducted to evaluate on-site performance of PKO-P.

\section{ACKNOWLEDGEMENT}

The authors thank to UiTM postgraduate student, Nastasa Samat for giving full cooperation to conduct this research and collaborator from UKM Prof Dr Khairiah Haji Badri for the guidance and knowledge sharing. This research was financially supported by iRAGS grant from Universiti Teknologi Mara, UiTM.

\section{REFERENCES}

[1] Khairiah Haji Badri (2012). Biobased Polyurethane from Palm Kernel Oil-Based Polyol, Polyurethane, Dr. Fahmina Zafar (Ed.), InTech, DOI: 10.5772/47966. Available from: http://www.intechopen.com/books/polyurethane/biobasedpolyurethane-from-palm-kernel-oil-based-polyol

[2] Badri, K. H., Mat Amin, K. A., Khalid, N. K., Othman, Z. \& Abdul Manaf, K. (2006). Effect of Filler-To-Matrix Ratio on The Mechanical Strength of Palm-Based Biocomposite Board. Polymer International, 55: 190-195.

[3] Badri, K.H. \& Mat Amin, K. A. (2006). Oil Palm-Based Biocomposites. Journal of Oil Palm Research, (Special IssueApril 2006): 103-113.
[4] Badri, K. H., Othman, Z. \& Mohd Razali, I. (2005). Mechanical Properties of Polyurethane Composites from Oil Palm Resources. Iranian Polymer Journal, 14 (5): 987-993.

[5] Badri, K. H., Othman, Z. \& Ahmad, S. H. (2004). Rigid Polyurethane Foams from Oil Palm Resources. Journal Of Materials Science, 39 (16-17): 5541-5542.

[6] Badri, K. H., Shahaldin, F. H. \& Othman, Z. (2004). Indigenous Coating Material From Palm Oil-Based Polyamide. Journal Materials Science Letters, 39 (13): 4331-4333.

[7] Badri, K. H. (2002). Preparation and Charaterization of Polyurethane Foam from RBD Palm Kernel Oil-Based Polyurethane Polyol and Oil Palm Empty Fruit Bunch Fiber as Filler. Proceeding of National Science Fellowship (NSF) Workshop, Petaling Jaya pg. 114-120.

[8] Badri, K. H., Ahmad, S. H \& Zakaria, S. (2000). Development of Zero ODP Rigid Polyurethane Foam From RBD Palm Kernel Oil. Journal Materials Science Letters, 19: 1355-1356.

[9] Badri, K. H, Ahmad, S. H. \& Zakaria, S. (2000). Thermal, Crystallinity and Morphological Studies on the Filled RBD Palm Kernel Oil Polyurethane Foam. Nuclear Science Journal of Malaysia, 18 (2): 57-62.

[10] Buzzi, O., Fityus, S., Sasaki, Y., Sloan S. (2010). Use of expanding Polyurethane Resin to Remediate Expansive Soil Foundation. Can Geotech Vol 47.

[11] Popik, M., Trout, M., Randall W. B. (2010). Improving Soil Stiffness Beneath Pavements using Polyurethane Injection. Annual Conference of the Transportation Association of Canada

[12] Whitlow, R. (2004). Basic Soil Machanics (4th ed). Jurong, Singapore: Pearson Education Ltd, publishing as Prentice Hall. 